Verlag und Bearbeiter hoffen somit, daß das vorliegende Werk, das sich in der Schweiz schon in vielen Auflagen sehr bewährt hat, bei Lehrenden und Lernenden der gewerblichen Berufsschulen Deutschlands den gleichen Anklang finden wird und so für den jungen Menschen in der Ausbildung eine wertvolle Hilfe werden kann, auch zu späterer Mitarbeit am Wiederaufbau Deutschlands.

August 1949

H. Bornemann, Baurat

Dozent für Elektrotechnik

an der Ingenieurschule Beuth, Berlin

\title{
Vorwort zur dritten deutschen Auflage
}

Die vorliegende dritte deutsche Auflage ist die für deutsche Verhältnisse überarbeitete 11. Schweizer Auflage. Wie aus dem Vorwort von Herrn Däschler hervorgeht, wurde sie vollständig von ihm überarbeitet und wesentlich ergänzt. In dieser 3. deutschen Auflage wurden die VDE-Vorschriften und die Normblätter in besonderem Druck gesetzt, um ihre Wichtigkeit herauszuheben. Die Multiplikationspunkte in den Buchstabenformeln wurden gemäß DIN 1338 fortgelassen und alle Formeln entsprechend dem Normblatt DIN 1313 als sogenannte Größengleichungen geschrieben, d. h. bei jeder Zahlenwertangabe steht die zugehörige Dimension.

Auch ich würde mich freuen, wenn diese 3. Auflage einen ebenso freudigen Leserkreis finden würde, wie die beiden vorangegangenen.

H. Bornemann, Baurat i.R. ehem. Dozent für Elektrotechnik an der Staatl. Ingenieurschule Beuth, Berlin 